\title{
PERFORMANCE EVALUATION OF LOCALLY ASSEMBLED SOLAR POWERED IRRIGATION PUMP Hegazi, A. ${ }^{(1)}$, Awady, M. N. ${ }^{(2)}$, Hegazi, M. M. ${ }^{(2)}$ and Elgindy, R. W. ${ }^{(3)}$
}

ABSTRACT

Solar powered pump motor is a special DC motor normally manufactured in advanced countries such as Germany, USA, etc. To obtain PVP (Photovoltaic pumps) users in Egypt must import them from abroad. This study was conducted to modify a locally assembled solar powered irrigation pump. A direct coupled photovoltaic pumping system has been assembled and installed in the Egyptian desert in Inshas at the Nuclear Research Center $\left(31^{\circ} 21^{\prime}\right.$ E, $\left.30^{\circ} 17^{\prime} N\right)$. Eight hundred Watts DC motor with brushes was modified to match unsteady PV generator current output. The DC motor was supplied with PV generator current, which was divided between 9 and 4 modules. The 9 modules were connected to the rotor and the 4 modules to the stator field. The motor was tested without load for several hours in situ and was coupled to the centrifugal pump. Pump-set output was tested at different insolation levels and a relationship was carried out from observed data. Monthly solar insolation for ten years period was obtained from a program named "Meteo-Norm" software in order to predict and calculate the average daily pumping system water delivery in cubic meters per month. The system showed flexible response to the PV generator output power demonstrated in DC motor RPM and consequently water delivery.

Keywords: photovoltaic, PV pumping, directly coupled pump.

\section{INTRODUCTION}

lternative energy sources were undermined until fuel prices
started to rise significantly in the last few years. High initiating
costs of PV generators was a limiting factor for those users to utilize such renewable and clean energy source. Even though this solar technology may have a higher starting cost than that of conventional fossil fuel, the low maintenance and operation cost and the ability to operate without fuel make the solar powered systems cheaper to keep.

(1) Ass. lecturer, soil \& water Res. Center, Atomic Energy Auth.

(2) Prof. Emt., Ag. Eng. Dept., Fac. Ag., A. Shams U.

(3) Prof. and Head Soil and Water Res. Dept., Atomic E. Authority. 
Many researches were carried out to increase PV systems efficiencies in other words to decrease the initiating costs. PV pumping system is a promising step towards sustainable irrigation since crop water requirement and solar power generation are closely correlated to radiation.

(Mayer and Müller, 1996). The least expensive method of pumping water using PV energy is by directly connecting a DC motor (Merino et al., 2008). This study concerns using locally assembled pumping system powered by PV to provide water for irrigation as a cost-effective parameter in the PV pumping system. System efficiencies and pump discharge was studied. Photovoltaic Pumping system (PVP) was related with daily solar radiation intensity derived from "Meteo-Norm" software. Solar irrigation system needs to take account of the fact that demand for irrigation water will vary throughout the year. Pande, et al. (2003), designed and developed a solar photovoltaic pump (PVP) operated drip irrigation system for growing orchards in and region considering different design parameters, like pumps size, water requirements, and the diurnal variation in the pressure of the pump due to change in irradiance and pressure compensation in the emitters. Short and Thompson (2003), showed that solar powered water pumping has the potential to bring sustainable supplies of potable water to millions of people in developing countries. Mueller et al. (1998) said that due to the high initial costs of PV-generators the power requirement of the system has to be minimized from the beginning. Since the hydraulic power is the product of flow and pressure, following targets are set:

- Reduction of the required flow by avoidance of water losses and

- Reduction of pressure loss by an optimum hydraulic system layout.

Betka and Moussi (2004), stated that performances of a photovoltaic pumping system based on an induction motor are degraded once insolation varies far from the value called nominal, where the system was sized. Bione et al. (2004), proposed a photovoltaic pumping systems with solar tracking, coupled to low concentration cavities, as a viable alternative to reduce the final cost of the pumped water volume. 
PVP's initiation costs are a limiting factor to be utilized by farmers for irrigation. Studies were always concerning the increase of PVP system efficiencies as an indirect way to decrease the costs. In this study, local market materials were matched to construct a DC motor to drive a centrifugal pump as a replacement for pumping systems readily imported.

\section{MATERIALS AND METHODS}

Experiments were conducted at Nuclear Res. Center; Inshas, Egypt (أنشاص). Two sets of Siemens M55 modules with max. out power 55 watt, were used to generate the power to run motor pump. First set was 9 modules each three in series, while the other set was 4 modules each two in series. Multimeter, tachometer and pyranometer were used to measure generator output (Voltage and DC current), DC motor speed (rpm) and solar intensity $\left(\mathrm{W} / \mathrm{m}^{2}\right)$ respectively.

A series DC motor (Fig. 1) was coupled to a centrifugal pump as shown in Fig. (2). Schematic drawing of pumping-set in site shown in Fig. (3). Motor was modified to respond smoothly to the low current supply PV generator along the daytime through the months. The motor starts smoothly when the solar intensity reaches $495 \mathrm{~W} / \mathrm{m}^{2}$ (threshold level).

Meteo-Norm climatological database for solar energy applications were used to get solar radiation values for the site under investigation. These values, which provide solar radiation averages for 10 years (1995-2005), were used to determine the pumping system output as a relation between solar intensity and solar generator output power.

Preliminary experiment was conducted to acquire a relationship between PVP system outputs and solar-radiation intensity values; which could be rapidly differ from minute to minute during the day and through different seasons. Solar radiation, power consumption (as Voltage and Current), motor RPM and pump flow varied, while head was kept constant at 4 meter. 


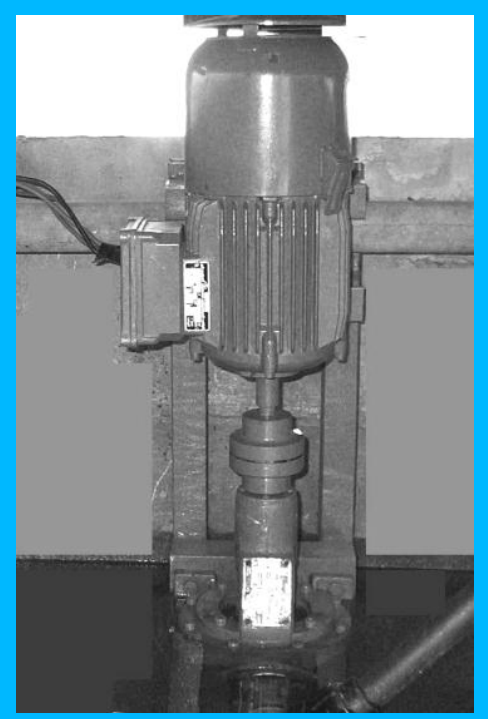

Fig. 1: The DC motor and the manufacturer power connection diagram.

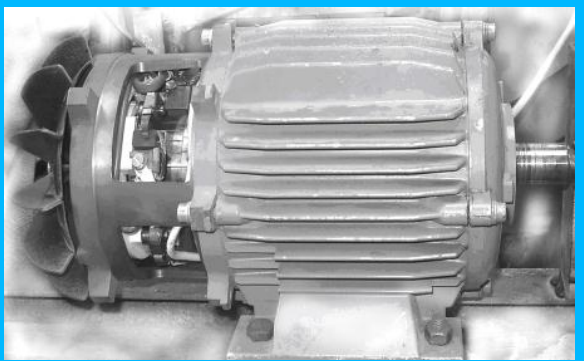

Gleichstrom-Nebenschluß-

motoren

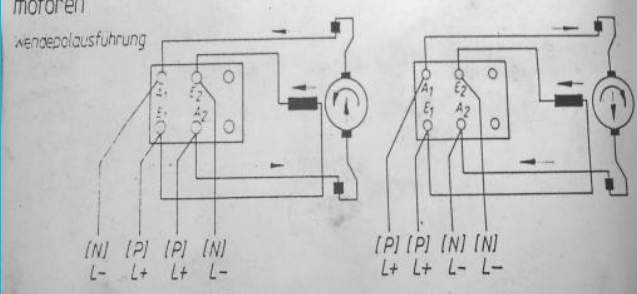

Fig. 2: Pump set fixed vertically on the basin at the experiment site.

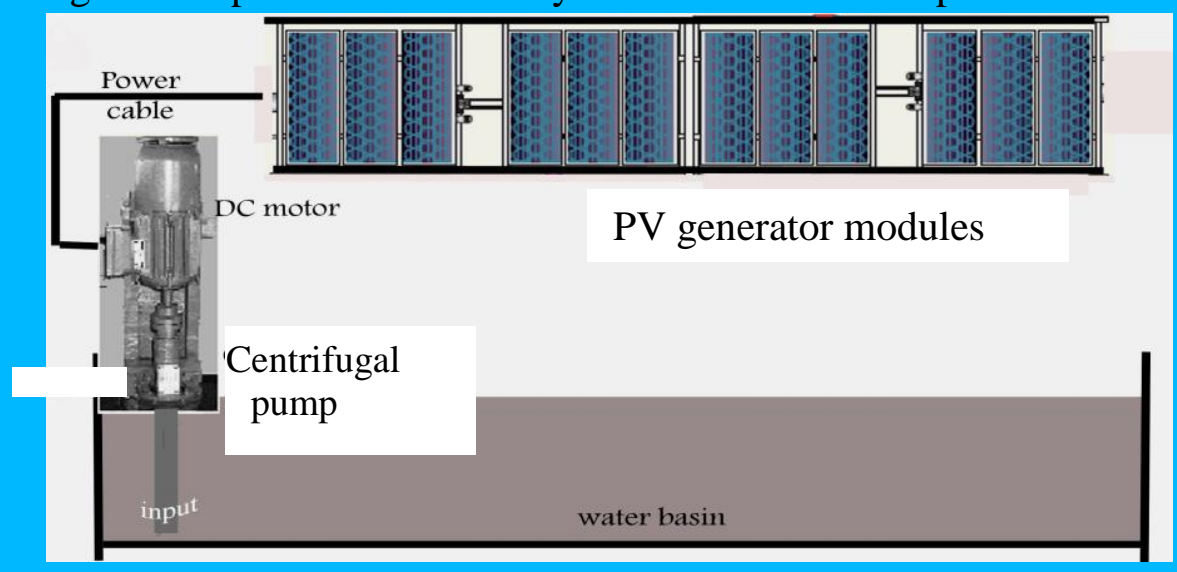

Fig. 3: Schematic drawing of pumping-set in site. 


\section{RESULTS AND DISCUSSIONS}

Measurements were performed in order to evaluate the Photovoltaic pumping system (PVP). Correlation relationships of different parameters affecting PVP system performance and characteristics were achieved. Fig. (4) Represents the motor power consumption at pumping discharge rate during a selected day in June month.

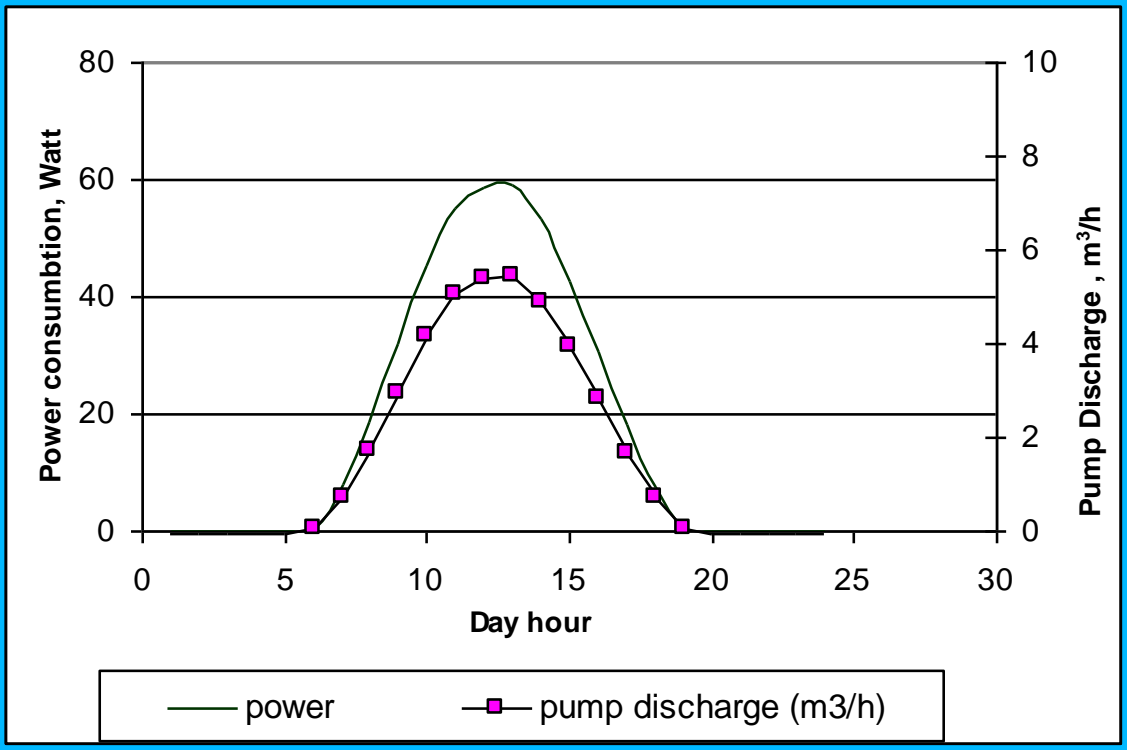

Fig. 4: Pump flow rate and power consumption through a selected day in July month.

Pump manufacturer characteristic curve indicating pump running speed at $1450 \mathrm{rpm}$, with rate of discharge $8 \mathrm{~m}^{3} / \mathrm{h}$ and 4 meter head with efficiency about $40 \%$. Alternatively maximum measured speed was less than 1200 rpm and the maximum calculated pump efficiency using equation (1) was less than $40 \%$, Fig. (5).

Maximum required power $($ Watt $)=\frac{Q \quad \max \times \rho \times g \times h}{\eta_{t}} \ldots$ (1)

Where

$\mathrm{Q}_{\max }$ is Maximum flow delivered $\left(\mathrm{m}^{3} / \mathrm{s}\right)$

$\mathrm{h}$ is static head (m)

$\rho$ is water density, $\mathrm{kg} / \mathrm{m}^{3}$

$\mathrm{g}$ is gravity $\left(\mathrm{m} / \mathrm{s}^{2}\right)$ 
$\eta_{\mathrm{t}}$ is Total system efficiency at maximum flow, $\%$

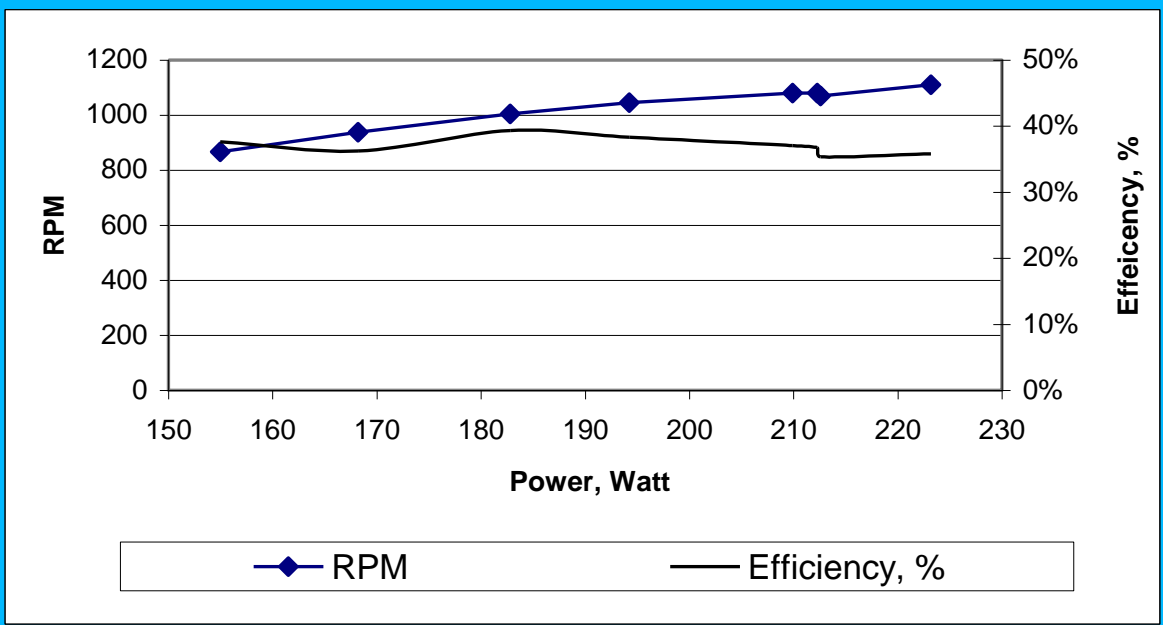

Fig. 5: Motor speed and pumping system efficiencies at different power consumption values.

Linear relationships concerning solar radiation values $\left(\mathrm{W} / \mathrm{m}^{2)}\right.$ with both pump discharge $\left(\mathrm{m}^{3} / \mathrm{h}\right)$ and DC motor power consumption (Watt) were obtained using curve fitting equation $(600 \leq \mathrm{R} \leq 1050)$ as illustrated in Fig. $(6,7)$ respectively.

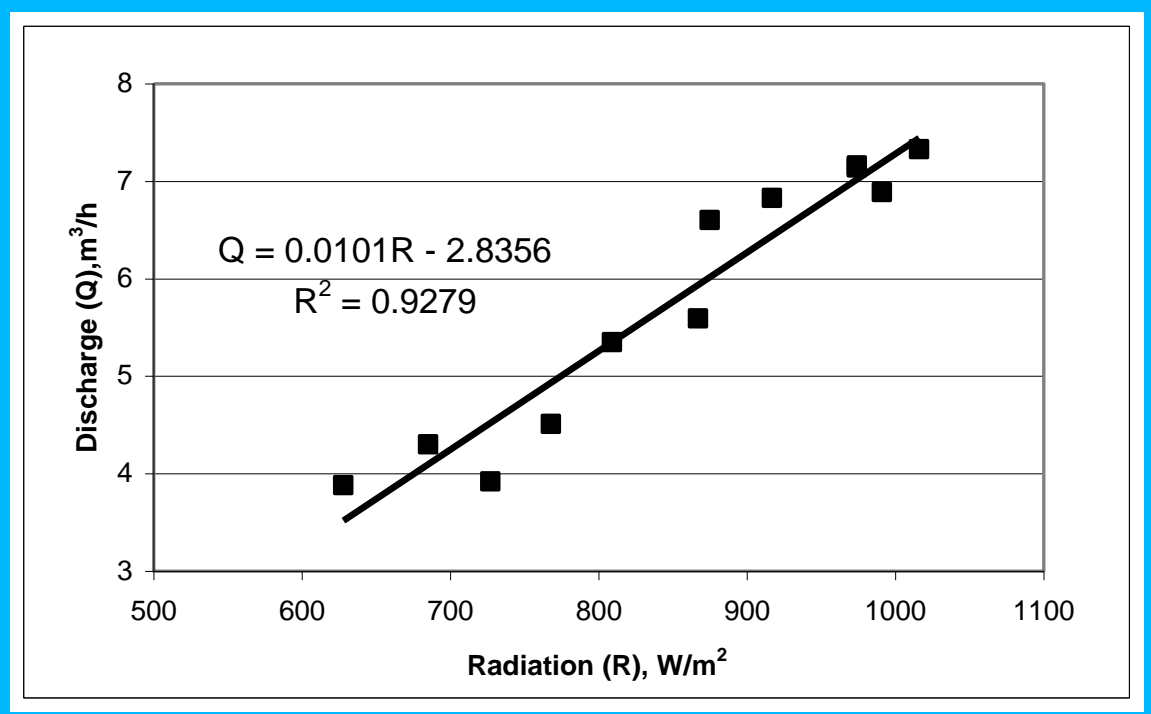

Fig. 6: Pump delivery correlated to solar radiation. 


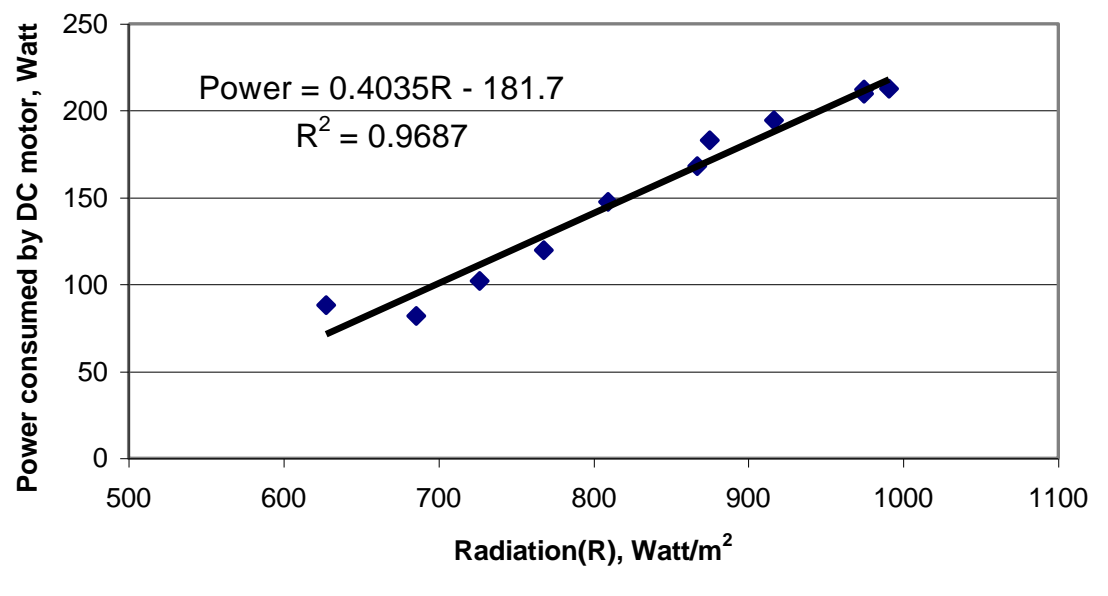

Fig. 7: DC motor power consumption (Watt) with different solar radiation values.

Daily solar radiation average for each month was derived from "MeteoNorm" database for area under investigation. Calculated pump output flow at certain solar radiation values were determined using empirical equation (2) and was plotted for all months. Fig. (8) represents a selected month (June) as an case in point.

$$
Q=0.0101 R-2.8356
$$

Where:

$\mathrm{Q}$ is the pump discharge $\left(\mathrm{m}^{3} / \mathrm{h}\right)$

$\mathrm{R}$ is the solar radiation $\left(\mathrm{W} / \mathrm{m}^{2}\right)$.

The total water amount through the year was calculated as drawn in Fig. (9). The figure shows differences between months, higher in summer, and this need to be compared to crop evapotranspiration, $\mathrm{ET}_{\mathrm{c}}$, in order to identify the area to be cultivated without water shortage leading to water stress for the plants. Pumping system can deliver between 60 rising up to $80 \mathrm{~m}^{3} /$ day, while in winter months was fluctuating from les than 10 $\mathrm{m}^{3} /$ day rising up to $60 \mathrm{~m}^{3} /$ day. 


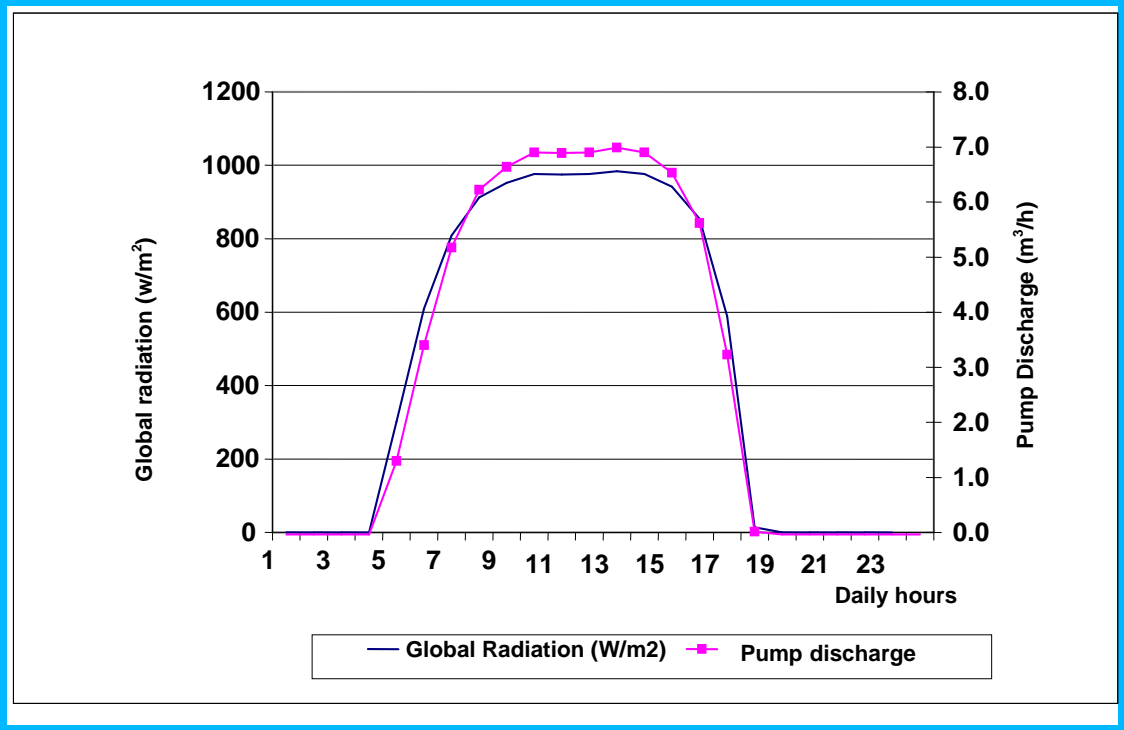

Fig. 8: Hourly average radiation (derived from Meteo-Norm software) and the computed pumping discharge for a selected month (June).

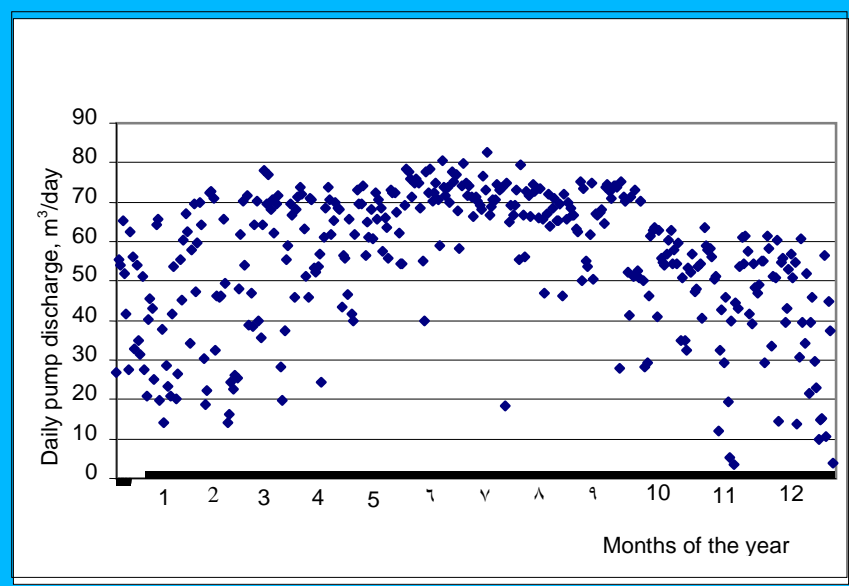

Fig. 9: PVP hourly discharge through the year.

\section{CONCLUSION}

Experiments were conducted using direct coupled photovoltaic pumping system. A locally assembled solar powered irrigation pump was modified to match the PV generator variable output. Different relations were carried out in order to evaluate the performance of the motor and the pump to meet the water needs of a certain desertic area in Egypt. The 
results show high relation between pumping system delivery and solar radiation values. Hourly based average measurements for ten years (19952005) of solar radiation values were linked to PVP discharge to estimate the whole year water output of the system. Pump discharge was $7.33 \mathrm{~m}^{3} / \mathrm{h}$ at 4 meter head with $1016 \mathrm{~W} / \mathrm{m}^{2}$ soalr intensity. Pumping system efficiency was less than $40 \%$.

\section{REFERENCES}

Betka A. and A. Moussi; 2004. Performance optimization of a photovoltaic induction motor pumping system, Renewable Energy, 29:2167-2181.

Bione J.; O. C. Vilela and N. Fraidenraich; 2004. Comparison of the performance of PV water pumping systems driven by fixed, tracking and V-trough generators, Solar Energy, 76:703-711.

Mayer O. and J. Mueller; 1996. Photovoltaic und ihre anwending in Bewaesserungs-systemen, Wasserwirtschaft, 86(4): 190-193.

Merino, G. G.; L. O. Lagos and J. E. Gontupil; 2008. Monitoring and evaluation of a direct coupled photovoltaic pumping system, App. Eng. in Ag., 24(3): 277-284.

Mueller J.; S. Algohary, A. Hegazi and K. Koeller; 1998. Solar power drip Irrigation for orchards in remote areas, 13th Int'l Congress on Agric. Eng., Rabat (Morocco), 4:279-287.

Mueller J.; K. Koeller, S. Algohary and A. Hegazi; 1998. Solar power drip Irrigation in Egypt, Landtechnik, 53(3) : 138-139.

Pande P.C., A.K. Singh, S. Ansari, S.K. Vyas and B.K. Dave; 2003. Design development and testing of a solar PV pump based drip system for orchards ,Renewable Energy, 28, 385-396.

Short, T.D. and P. Thompson;- 2003, Breaking the mould: solar water pumping -the challenges and the reality, Solar Energy, 75: 1-9. 


\section{الملخص العربى \\ تقيم الأداء لمضخة ري تعمل بالطاقة الشمسية مجمعة محليا \\ أحمد حجازي، محمد ن. العوضى، محمود م. حجازي، \\ رشدي و. الجندى.}

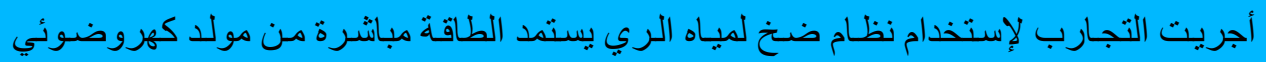

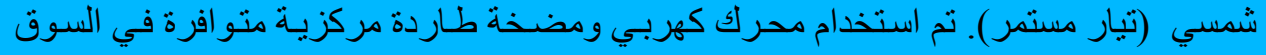

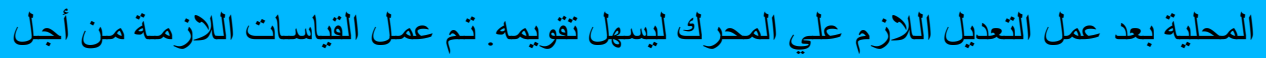

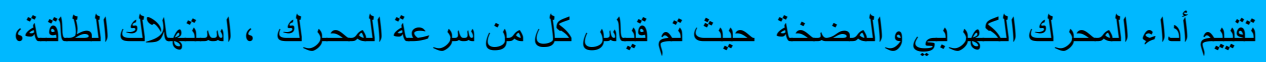

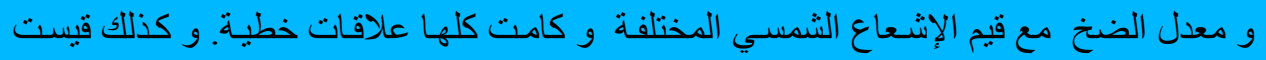

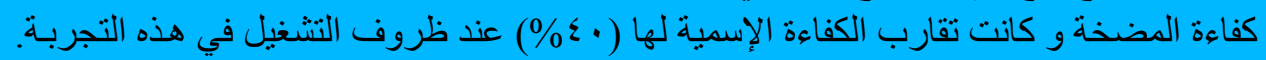

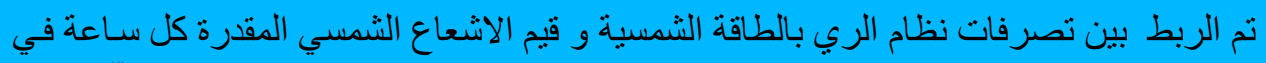

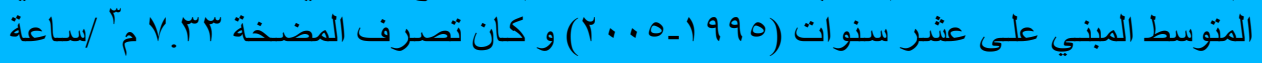

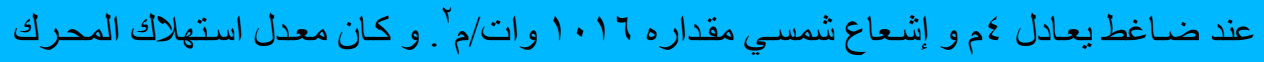

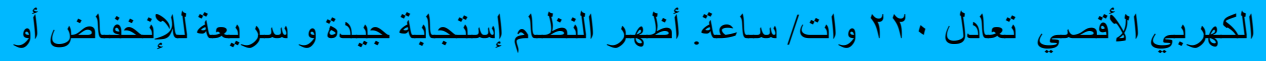

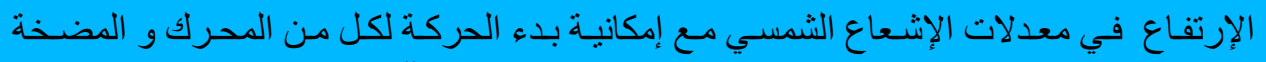

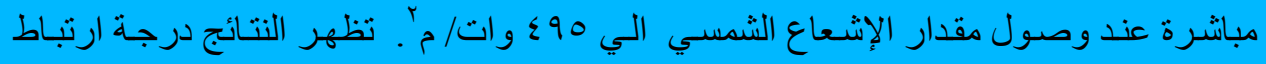

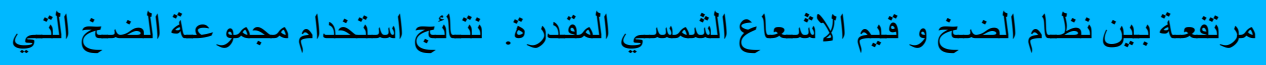
تعمل بالطاقة الثمسية المجمعة محليا كانت مشجعة لتنبني تطويرو تصنيع مثنيلاتها محليا. 